\title{
Despesas municipais no sul do Brasil: uma abordagem via painel de dados
}

\author{
William Gledson e Silva* \\ Jonilson de Souza Figueiredo** \\ Francisco Danilo da Silva Ferreira ${ }^{* * *}$ \\ Luís Abel da Silva Filho ${ }^{* * * *}$
}

Resumo. A descentralização fiscal no Brasil assistida a partir da Constituição Federal (CF) de 1988 permitiu maior autonomia aos entes subnacionais em um contexto de controvérsias teóricas de magnitude nada desprezível. Diante da descentralização fiscal brasileira e com objetivo de auxiliar na orientação do uso das receitas auferidas pelas unidades Federal, estaduais e municipais, instituiu-se a Lei de Responsabilidade Fiscal (LRF), em maio de 2000. Diante do contexto de descentralização e de orientação das despesas municipais, este artigo tem como objetivo analisar os dispêndios dos municípios do Sul do Brasil, comparativamente, levando em consideração as orientações instituídas pelas regulamentações supracitadas. Os dados são oriundos da Secretaria do Tesouro Nacional (STN) e compreendem os anos de 2007 a 2010. Período compreendido pelo segundo Governo Lula. Metodologicamente, recorre-se a uma revisão de literatura e em seguida ao método de dados em painel. Os principais resultados revelam haver forte dispêndio com pessoal, deixando a menor participação para investimento e despesas com assistência social. Isso implica na divergência entre a orientação da LRF e das ações políticas estabelecidas na referida região. Diante disso, percebe-se que ainda há forte orientação de gastos à livre ação dos gestores municipais e reduzido investimento como forma de multiplicação do desempenho econômico via ação pública municipal.

Palavras-chave: Descentralização fiscal; despesas municipais; Sul do Brasil.

Classificação JEL: H0; H20; H29.

\footnotetext{
* Mestre em Economia pela Universidade Federal do Rio Grande do Norte (UFRN). Professor do Departamento de Economia da Universidade do Estado do Rio Grande do Norte (UERN). Endereço eletrônico: williamgledson@uern.br.

** Mestrando em Economia pela Universidade Federal do Rio Grande do Norte (UFRN). Endereço eletrônico: jonilsonufrn@yahoo.com.br

${ }^{* * *}$ Graduando em Economia pela Universidade do Estado do Rio Grande do Norte (UERN). Endereço eletrônico: ffdanilloferreira@gmail.com

**** Mestre em Economia pela Universidade Federal do Rio Grande do Norte (UFRN). Professor do Departamento de Economia da Universidade Regional do Cariri (URCA). Endereço eletrônico: abeleconomia@hotmail.com
} 


\section{Considerações iniciais}

O campo das finanças públicas, via de regra, procura examinar o comportamento das administrações governamentais e/ou das empresas de natureza pública, de modo a possibilitar uma compreensão de como os recursos alocados socialmente são gastos, inclusive estabelecendo categorias (classificações) de como se arrecada e se despende as chamadas receitas dos governos.

Sabe-se, portanto, que existem implicações institucionais que influenciam os chamados mecanismos fiscais (receitas e despesas), isto é, do ponto de vista do amparo legal, o comportamento das gestões públicas está baseado em limites impostos pelas regras, onde no Brasil são decorrentes da Constituição Federal (CF) de 1988. Assim, ela exerce esse papel, institucionalizando o descentralismo fiscal, dando uma liberdade administrativa maior aos entes federativos do país, sobretudo aqueles de dimensão subnacional (Rangel, 2003; Silva, 2009).

Os efeitos da CF de 1988 produziram elevação na autonomia decisória de estados e, principalmente municípios, cujas repercussões viabilizam as mais elevadas demandas por recursos originários de entes federativos de maior amplitude (como é o caso da União). Isso permitiu maior capacidade de financiar os gastos governamentais, não se observando restrições importantes para a contenção das despesas dos entes subnacionais, diante da maior participação de municípios e estados em recursos da União.

A nova agenda fiscal brasileira surge no linear do novo milênio: a Lei de Responsabilidade Fiscal (LRF) é implantada em 2000, cuja finalidade era disciplinar a administração pública no Brasil, impondo limites ao endividamento e restringindo as renúncias de recursos. Com isso, maior prudência na gestão dos déficits orçamentários, ampliação na transparência administrativa, dentre outras ações, criando uma regulamentação capaz de retificar as eventuais inconsistências institucionais presentes na CF de 1988 (Silva, 2009).

Nesse sentido, o estudo de Santolin et al. (2009) expressa que a LRF é rígida no que concerne aos aspectos punitivos, sendo que para as administrações subnacionais cumprirem os limites impostos pela legislação, normalmente, os gestores deveriam cortar gastos relacionados aos investimentos e/ou às áreas sociais, pois seria difícil - dada a rigidez em sua estrutura - reduzir os dispêndios com pessoal. Assim, a norma implantada em 2000 não se revestia de positividade.

Já Silva (2009) e Silva Filho et al. (2010) mostram que a LRF é plausível às administrações subnacionais brasileiras, visto que um ambiente fiscalmente mais prudente eleva as possibilidades de arrecadação própria, restringe as demandas por recursos transferidos que impõem dificuldades à união, inibe a expansão nos gastos principalmente no tocante ao custeio da máquina com folha de funcionários, ampliando o horizonte da aplicabilidade de políticas públicas com menores impactos, relativamente às contas públicas dos entes federativos.

Ante isso, este estudo se propõe a verificar o comportamento das despesas totais municipais per capita dos estados do Sul brasileiro, tomando 
como referência o período do segundo Governo Lula, já que se trata de uma série temporal marcada pela implementação do Programa de Aceleração do Crescimento (PAC) e a crise financeira internacional em 2008. Logo, procurase observar se os eventos econômicos antes mencionados provocaram algum tipo de implicação na gestão municipal dos entes estaduais enfatizados, em um ambiente fiscalmente mais austero, sendo tais aspectos o objeto de pesquisa aqui considerado.

A hipótese central do artigo, propõe que as despesas totais municipais per capita dos estados da região Sul brasileira são explicadas, relativamente, em maior grau pelos gastos com pessoal por habitante, em face aos dispêndios sociais e com investimento per capita, em virtude das características sócio econômicas regionais herdadas historicamente.

As motivações quanto à realização deste trabalho decorrem de alguns aspectos específicos: em primeiro lugar, nota-se a existência de pesquisas que refletem sobre o comportamento das despesas municipais para diferentes estados brasileiros, a fim de estabelecer análises comparativas entre esses entes; em segundo lugar, observa-se uma escassez de estudos sobre municípios do Sul do país, numa perspectiva comparada, nos anos do segundo Governo Lula. Outro aspecto é recorrente da utilização do modelo de dados em painel, com vistas a realizar um confronto comportamental entre os entes municipais de cada estado, a partir de dados da Secretaria do Tesouro Nacional (STN).

Nessa perspectiva o objetivo desta pesquisa é analisar como se comportam as despesas municipais dos estados do Sul do Brasil, de modo comparativo, tendo em vista os aspectos institucionais presentes na LRF e CF de 1988. Logo, a partir dos gastos com pessoal, investimento e aqueles orientados ao social (tomados por habitante), entre os anos de 2007 a 2010, intervalo de tempo esse que compreende o segundo Governo Lula, procura-se medir o comportamento das despesas totais per capita.

Para atingir o objetivo proposto pelo estudo, o artigo está assim estruturado: além das considerações iniciais, no item posterior, apresentam-se os fundamentos teóricos sustentadores da investigação; a seguir, na terceira seção, mostram-se os procedimentos metodológicos essenciais ao trabalho; dando sequência, na quarta seção, exibem-se os resultados alcançados pela pesquisa, em seguida, na quinta seção, tecem-se as considerações finais e as consequentes recomendações.

\section{Despesas municipais em um ambiente fiscal controlado}

Neste item, pretende-se discutir o comportamento dos gastos governamentais, tomando como referência o aspecto institucional ligado ao descentralismo fiscal. Logo, o comportamento dos dispêndios de natureza pública no Brasil, atualmente, encontra-se em um contexto restrito, em virtude das limitações impostas pela Lei de Responsabilidade Fiscal.

Antes, porém, considere-se que a federação brasileira, que é composta por instâncias de governo (União, Estados, Distrito Federal e os Municípios), no 
final da década de 1980, vê surgir a chamada Constituição Federal (CF) de 1988. Sua força institucional, dentre outras situações, viabiliza a descentralização de recursos e competências, partindo de unidades federativas de maior amplitude para as de menor amplitude (Silva, 2009).

Ressalte-se que em uma federação, as unidades componentes dela estabelecem relações federativas, onde as gestões governamentais distribuem entre si os recursos gerados via tributação e as competências administrativas públicas. Desse modo, transferem-se recursos a esses elementos ligados aos entes federativos das diferentes abrangências espaciais, de uma forma mais ou menos autônoma, caracterizando-se respectivamente o descentralismo ou centralismo fiscal (Rezende, 2001; Silva Filho et al. 2010).

Assim, estudos como os de Afonso e Serra (1999), Afonso (2003), Rangel (2003) e Silva (2009), mostram que o processo de descentralismo fiscal possibilita o aumento da autonomia decisória dos entes subnacionais, criando um ambiente favorável para as despesas estaduais e principalmente municipais, as quais pudessem se elevar, uma vez que essas esferas passam a atender as demandas locais de modo mais significativo via transferências intergovernamentais.

Com efeito, a compreensão de que os gastos governamentais, na condição de uma modalidade bastante usual de política fiscal realizada pelos gestores governamentais subnacionais, tem a finalidade de produzir melhorias para os habitantes desses espaços, visto que:

[...] o gasto público gera rendas, algumas das quais poderiam beneficiar diretamente famílias pobres. Essas rendas criam outras rendas pelo processo multiplicativo de despesa-renda. Finalmente, despesas públicas geram transferências à população, que podem ser afetadas por meio de transferências monetárias, como ajuda social ou pagamentos de seguro social. (Araújo, 2006 p. 5).

Esses argumentos atestam que as despesas públicas geram melhorias ao contexto social, isto é, uma política fiscal de orientação expansionista. Isso provoca elevação no contingente de renda em circulação na economia, permitindo aos entes subnacionais a ocorrência de uma maior dinamicidade em suas atividades econômicas, sendo convergente com a tradição keynesiana explicitada em alguns modelos macroeconômicos de curto prazo.

Por extensão, Cintra (2005), Hermann (2006) e Lopreato (2007), revelavam que os dispêndios governamentais são cruciais para a consecução de um ambiente produtivo mais elevado. Ou seja, a chamada agenda fiscal no pós 1988 favoreceu ao expansionismo dos gastos e consequente geração de ritmos de atividade econômica mais elevada. Afinal, isto corresponde à verdade?

Diante dessas ponderações nota-se uma procura por um ambiente fiscalmente menos imprudente, er dizer, a hipótese keynesiana de que gastos governamentais elevados provocam dinamização produtiva nos diversos espaços que envolvem esse expediente pode ser questionado, pois existem compreensões capazes de sintetizar o funcionamento do setor público: 
O primeiro requisito é, portanto, que o governo resolva seus próprios problemas, isto é, que adote medidas que garantam estabilidade razoável ao seu fluxo de despesas. Se conseguisse isso, daria importante contribuição à redução dos ajustamentos necessários no resto da economia. (Friedman, 1985 p. 76).

Conforme a exposição anterior pode-se retomar discussões que relatam a necessidade de uma prudência maior na gestão das contas públicas, de modo a procurar preservar um ambiente em que as dívidas dos governos locais não se elevem a patamares insustentáveis, pondo limites ao descentralismo institucionalizado pela CF de 1988, cujo instrumento em desenvolvimento na atualidade é a LRF.

Nesse sentido, a enfatizada instituição surge como uma ferramenta capaz de atender as demandas existentes na discussão da agenda fiscal, a qual necessitava de uma melhor preservação da administração das contas públicas, principalmente pelo fato de que os entes subnacionais brasileiros, em virtude do ambiente institucional pouco conservador, guindado da CF de 1988, exibiam padrões de déficits significativos. Tais déficits eram financiados, na sua maioria, pelas transferências intergovernamentais, impondo à União dificuldades macroeconômicas não negligenciáveis (Lopreato, 2002; Rangel, 2003).

Para tanto, a LRF passa melhor regulamentar as gestões governamentais subnacionais, corrigindo as graves incongruências administrativas públicas do país. Diante disso, supõe-se um ambiente fiscalmente mais conservador, cujo marco temporal foi o ano de 2000, ponto de início das mudanças da gestão do setor público brasileiro (Lopreato, 2007; Sena e Rogers, 2007; Gerigk, 2008).

Entretanto, uma curiosidade institucional da LRF é apontada por Fioravante et al (2006), a qual revela que a maioria dos municípios brasileiros, notadamente de menor porte exibiam um padrão de gastos com pessoal (o maior gargalo fiscal do país antes da implantação da regulamentação) inferior aos limites impostos pela lei. Diante disso, há evidências de que as despesas governamentais com pessoal nos municípios brasileiros não eram um problema tão explícito como se acreditava. Afinal de contas, qual efeito da LRF sobre os gastos municipais atualmente?

Como esta pesquisa se enquadra entre os anos do segundo Governo Lula (2007/2010), caracterizados por fenômenos que, provavelmente, impactaram as finanças públicas do país, pergunta-se: quais efeitos no comportamento dos gastos municipais tiveram nessa gestão? Para elucidar esta inquietação, o estudo se propõe a investigar se os municípios dos estados do Sul do país apresentaram uma tendência: os dispêndios com pessoal foram mais ou menos pronunciados do que aqueles com gastos sociais e investimentos?

Assim, na seção subsequente é pretensão detalhar os procedimentos metodológicos a serem adotados no artigo, sistematizando a metodologia relativa ao modelo econométrico de dados em painel, que possibilita a análise, além de apontar os meios pelos quais os resultados esperados devem ser alcançados, a partir da hipótese central postulada na introdução deste trabalho. 


\section{Procedimentos metodológicos}

Nesta seção, torna-se importante discutir os aspectos metodológicos existentes na investigação, tendo em vista, apresentar, mais detalhadamente, a aplicação do modelo de dados em painel na análise das despesas totais per capita municipais dos estados do Sul brasileiro. Logo, faz-se necessário apresentar, de maneira breve, os principais aspectos existentes nesta metodologia econométrica, cuja tentativa é revelar os resultados a serem encontrados na pesquisa.

Antes, porém, faz-se necessário atestar que este estudo de natureza comparada tem perfil exploratório, considerando-se como tipos de pesquisa a bibliográfica, documental e o uso de amostragem. Quanto aos dados, esses são de origem secundária, dando mostras de que é fundamental a utilização de um método mais refinado na análise das informações coletadas junto ao FINBRA/ STN, o qual, por sua vez, refere-se ao modelo de dados em painel.

Ressalte-se ainda que haja necessidade de se adotar o chamado método do descarte, visto que, as variáveis selecionadas pela investigação são decorrentes das despesas municipais, sendo que nem todos eles publicam os resultados de seus exercícios fiscais na íntegra, durante os anos compreendidos no estudo, conforme procedem Matos Filho et al. (2008), que consideram esse expediente metodológico.

Com efeito, descartam-se aqueles municípios que não divulgaram todas as suas informações junto a STN, constituindo um universo de entes federativos por estado inferior ao número total dessas esferas municipais, cuja finalidade metodológica é permitir a formulação das variáveis essenciais constantes no artigo. Logo, a Despesa Total per capita (DT/pc), relaciona-se com o Dispêndio com Pessoal per capita (DP/pc), as Despesas com Investimento (DI/pc) e os Dispêndios Sociais per capita (DS/pc).

Diante disso, pode-se a partir de agora detalhar, de modo breve, o modelo de dados em painel. O restante da seção reserva essa discussão, que apesar de ser intensamente debatida na literatura econométrica, torna-se relevante discorrer um pouco acerca dessa metodologia, descrevendo o método analítico considerado na pesquisa.

Com a finalidade de verificar o comportamento das Despesas Totais per capita (DT/pc), a investigação recorre a um modelo de regressão múltipla, onde a DT/pc (variável dependente) é relacionada com três variáveis independentes como proxies das principais aplicações dos recursos públicos - Despesas com Pessoal per capita (DP/pc), Despesas com Investimento per capita (DI/pc), Despesas Sociais per capita (DS/pc).

Ressalte-se que é crucial medir o comportamento da DT/pc mediante o modelo linear (do tipo log-log), tendo em vista a captação dos efeitos exercidos pelas variáveis exógenas sobre a endógena em termos de elasticidade. Dessa forma, pode-se sistematizar econometricamente a relação entre as variáveis selecionadas para o estudo conforme o exposto na equação 1 que se segue: 


$$
\log \left(D T p c_{\mathrm{it}}\right)=\beta_{0}+\beta_{1} \log \left(\mathrm{DPpc}_{\mathrm{it}}\right)+\beta_{2} \log \left(D I p c_{i t}\right)+\beta_{3} \log \left(D S p c_{i t}\right)+\varepsilon
$$

Nota-se a presença dos parâmetros $\beta_{0}, \beta_{1}, \beta_{2}, \beta_{3}$, em que esses estabelecem diferentes graus de relação com a DT/pc (variável dependente), demonstrando a influência de cada rubrica de dispêndio sobre os gastos totais efetivados pelos municípios dos estados do Sul do Brasil, sendo o subscrito it a representação do diferencial de cada município da amostra coletada em cada ano pesquisado.

Faz-se necessário atestar que os dados em painel, que reúnem um modelo de corte transversal associado a séries de tempo, enquadram-se ao estudo em desenvolvimento, pois unidades federativas como os estados de Santa Catarina (SC), Paraná (PR) e Rio Grande do Sul (RS) contemplam um número expressivo de entes municipais, os quais podem ser analisados em diversos períodos, tendo sidos selecionados os anos do segundo Governo Lula. (Kennedy, 2009; Silva, 2009; Gujarati; Porter, 2011).

Com efeito, funcionalmente, a metodologia de dados em painel é constituída dos seguintes elementos: a variável explicada $Y$; as variáveis explicativas $X$; e o termo estocástico $\varepsilon$, submetidos a um subscrito duplo, em que $i$ significa a unidade seccional e $T$ o ponto no tempo, conforme a equação 2 a seguir. Correspondendo a $Y$ um vetor $\mathrm{n} T \mathrm{x} 1 ; X$ sendo do tipo $\mathrm{n} T \mathrm{x} K$, seja $K$, as variáveis analisadas; e $\varepsilon$, um vetor do tipo $\mathrm{n} T \mathrm{x} 1$. De maneira que o modelo genérico pode ser expresso: $y=X \beta+\varepsilon$, onde os parâmetros $\beta$, são apresentados num vetor $K x 1$.

$$
y_{i}=\left\|\begin{array}{l}
y_{i 1} \\
y_{i 2} \\
\vdots \\
y_{i T}
\end{array}\right\| X_{i}=\left\|\begin{array}{cccc}
X_{i 1}^{1} & X_{i 1}^{2} & \cdots & X_{i 1}^{k} \\
X_{i 2}^{1} & X_{i 2}^{2} & \cdots & X_{i 2}^{k} \\
\vdots & \vdots & \ddots & \vdots \\
X_{i t}^{1} & X_{i t}^{2} & \cdots & X_{i t}^{k}
\end{array}\right\| \varepsilon=\|\llbracket\| \begin{gathered}
\varepsilon_{i 1} \\
\varepsilon_{i 2} \\
\vdots \\
\varepsilon_{i t}
\end{gathered} \|
$$

Assim, a metodologia de dados em painel permite amenizar alguns problemas advindos das estimações via método dos Mínimos Quadrados Ordinários (MQO), tais como: a heterogeneidade das unidades (no painel ela é explícita) e a questão das variáveis omitidas, à medida que, simultaneamente, trata os dados de série e de corte, minimiza-se esse problema. (Greene, 2003).

Sabendo-se que a discussão a respeito dos dados em painel é bastante vasta, resume-se neste artigo a apresentação de alguns aspectos sobre painéis equilibrados (cujo número de observações é o mesmo para as unidades seccionadas). No que tange ao processo de estimação da regressão, sumariamente, aponta-se: o estimador agregado, o de efeitos fixos, e o de efeitos aleatórios.

A metodologia de coeficientes constantes ou estimador agregado é o caso mais trivial, que consiste no empilhamento de todas as observações disponíveis e, desprezando a estrutura de painel, estimando via MQO; Na tentativa de solucionar o problema decorrente pelo estimador agregado, pode-se utilizar o modelo de efeitos fixos, no qual o intercepto difere para cada unidade seccional, mas são invariantes no tempo, assumindo assim a presença de heterogeneidade e esse deve ser estimado via MQO; Finalmente, diferente dos efeitos fixos, os 
efeitos aleatórios não necessitam da inserção de parâmetros diferenciáveis, contrariamente, trata o intercepto como sendo uma variável aleatória de valor médio, em que a diferença das unidades seccionais se reflete num termo de erro idiossincrático. (Kennedy, 2009; Silva, 2009; Gujarati; Porter, 2011).

Comumente, a literatura sugere a realização de testes para a obtenção de estimações eficientes e consistentes, por exemplo, o teste $F$ restrito e o teste de Hausman. Assim, o teste $\mathrm{F}$ restrito associa o estimador agregado (modelo restrito) com o de efeitos fixos (modelo sem restrições). Sistematizando o $\mathrm{R}^{2}$ obtido pelo modelo de efeitos fixos, $R_{S R}^{2}$, e o aferido pelo estimador de coeficientes constantes, $R_{R}^{2}$, averigua-se a hipótese de que os interceptos diferenciais passam a ser iguais, e, portanto, o estimador agregado é o melhor. Seja o número de restrições $m$; das observações $n$; e dos parâmetros $k$.

$$
F=\frac{\left(R_{S R}^{2}-R_{R}^{2}\right) / m}{\left(1-R_{S R}^{2}\right) /(n-k)} \sim F_{[m,(n-k)]}
$$

O teste de Hausman, por sua vez, confronta o estimador de efeitos aleatórios com o de efeitos fixos. Essa estatística - de distribuição assintótica $X^{2}$ (qui-quadrado) - atua frente à hipótese nula de que o estimador de efeitos aleatórios é o que melhor se adéqua ou, de modo subjacente, que tais estimadores não se diferenciam significativamente. Seja $\hat{\beta}_{E A}$, o estimador de efeitos aleatórios e $\hat{\beta}_{E F}$, o estimador de efeitos fixos. Matematicamente:

$$
H=\left(\hat{\beta}_{E A}-\hat{\beta}_{E F}\right)^{\prime}\left(\sum_{E F}-\sum_{E A}\right)^{-1}\left(\hat{\beta}_{E A}-\hat{\beta}_{E F}\right)^{\prime}
$$

Uma vez discutidos os procedimentos metodológicos, os quais apresentaram, sinteticamente, o modelo de dados em painel, sugere-se na próxima seção a exibição dos resultados alcançados no estudo, cuja expectativa é analisar a luz dos fundamentos teóricos e metodológicos até então ressaltados, como se comportam os estados da região Sul do Brasil do ponto de vista de suas despesas em nível municipal, durante o segundo Governo Lula.

\section{Notas sobre despesas municipais dos estados do Sul}

Após a exposição metodológica desenvolvida no item precedente, pretende-se a partir de agora discutir o comportamento das despesas totais per capita municipais dos estados do Sul do país, cuja metodologia adotada provém do modelo de dados em painel. Logo, o custeio da máquina pública municipal presente nos estados da pesquisa, de fato é superior aos dispêndios com investimento e social?

De posse dos resultados constantes nas tabelas 1, 2 e 3, nota-se claramente que as despesas com pessoal nos municípios da região Sul do Brasil são muito mais elevadas se comparado às demais rubricas consideradas na investigação. Nesse sentido, as análises desenvolvidas por Santolin et al. (2009) 
e Silva (2009) são compatíveis com o alcançado no atual trabalho, cuja explicação a esse fato decorre de uma elevada necessidade do setor público em financiar seus gastos com folha de pagamento (funcionários efetivos ou temporários), caracterizando-se dessa forma na rubrica de maior participação na DT/pc, a partir dos municípios analisados.

Ressalte-se ainda que todos os entes se comportaram de maneira bastante similar, isto é, as despesas destinadas aos investimentos e as áreas sociais são essencialmente menores do que os dispêndios com o custeio da máquina, dando mostras de que os governos locais possuem elevado grau de rigidez no âmbito de seus quadros de funcionários, mesmo em um período no qual o Brasil vivenciou uma dinâmica de crescimento orientada pelo setor público via PAC.

Faz-se necessário salientar que a escolha dos resultados mediante a opção pelos efeitos fixos, em detrimento aos efeitos aleatórios, deu-se em virtude dos primeiros terem se apresentado mais significativos a partir do constatado no teste de Hausmann, conforme discussão desenvolvida na seção 3 deste artigo. Além disso, nota-se que o $\mathrm{R}^{2}$ para o conjunto dos municípios dos estados da região Sul é bastante significativo, viabilizando as inferências constantes no estudo.

Especificamente, quanto às despesas com pessoal per capita, observase que no Paraná, ainda que de modo sutil, foi o estado que apresentou o mais reduzido montante de gastos dedicados ao pagamento dessa rubrica, em que o aumento de $\mathrm{R} \$ 1,00$ na $\mathrm{DP} / \mathrm{pc}$ provocou uma elevação da ordem de $\mathrm{R} \$ 0,66$ na $\mathrm{DT} / \mathrm{pc}$ (coeteres paribus). Com efeito, constatou-se que os municípios gaúchos exibiram uma elevação na DT/pc em torno de $\mathrm{R} \$ 0,71$ a cada aumento unitário na $\mathrm{DP} / \mathrm{pc}$ e os entes catarinenses, os que mais gastaram com folha de funcionários na região Sul, tiveram aproximadamente um acréscimo de $\mathrm{R} \$ 0,79$ na $\mathrm{DT} / \mathrm{pc}$ decorrente de uma ampliação unitária na DP/pc.

Do ponto de vista das despesas com investimento per capita, verificouse que as entidades municipais paranaenses demonstraram a menor propensão aos dispêndios dedicados com a enfatizada rubrica, sendo da ordem de $\mathrm{R} \$ 0,08 \mathrm{a}$ expansão na DT/pc proveniente do crescimento unitário da DI/pc. No tocante aos municípios gaúchos, esses revelaram um incremento de aproximadamente $R \$$ 0,13 na $\mathrm{DT} / \mathrm{pc}$ advindo do aumento de $\mathrm{R} \$ 1,00$ na $\mathrm{DI} / \mathrm{pc}$, restando às entidades de SC uma ampliação na $\mathrm{DT} / \mathrm{pc}$ em torno de $\mathrm{R} \$ 0,14$ provocada pela expansão unitária na DI/pc.

Já no que diz respeito às despesas sociais per capita, os entes federativos do PR tiveram o melhor desempenho no contexto social, visto que a DT/pc aumentou em torno de $\mathrm{R} \$ 0,13$ a cada incremento unitário na DS/pc. Assim, os municípios gaúchos apresentaram um patamar de elevação aproximado de apenas $R \$ 0,06$ a cada acréscimo de $R \$ 1,00$ na DS/pc e, por sua vez, os municípios catarinenses exibiram o pior resultado no contexto social, em que a elevação da ordem de $\mathrm{R} \$ 0,01$, aproximadamente, na DT/pc foi provocada através do aumento unitário na DS/pc. 
Tabela 1 - Resultados estimados das despesas totais, per capita, municipais do Paraná (2007-2010)

\begin{tabular}{|c|c|c|c|}
\hline \multirow[b]{2}{*}{ Variável* } & \multicolumn{3}{|c|}{ Técnica de estimação com dados em } \\
\hline & Estimador & Efeito fixo & Efeito \\
\hline Intercepto & $\begin{array}{r}1.512077 \\
(0.077637)\end{array}$ & $\begin{array}{r}1.674448 \\
(0.088497)\end{array}$ & $\begin{array}{r}1.577240 \\
(0.076991)\end{array}$ \\
\hline Despesa com pessoal per capita & $\begin{array}{r}0.669337 \\
(0.014561)\end{array}$ & $\begin{array}{r}0.660190 \\
(0.016361)\end{array}$ & $\begin{array}{r}0.666145 \\
(0.014327)\end{array}$ \\
\hline $\begin{array}{l}\text { Despesa com investimento per } \\
\text { capita }\end{array}$ & $\begin{array}{r}0.104027 \\
(0.007410)\end{array}$ & $\begin{array}{r}0.081289 \\
(0.007956)\end{array}$ & $\begin{array}{r}0.093907 \\
(0.007150)\end{array}$ \\
\hline Despesa social per capita & $\begin{array}{r}0.129172 \\
(0.005636)\end{array}$ & $\begin{array}{r}0.133436 \\
(0.005386)\end{array}$ & $\begin{array}{r}0.131292 \\
(0.005140)\end{array}$ \\
\hline $\mathrm{R}^{2}$ & 0.810797 & 0.893163 & 0.814457 \\
\hline Estatística F & 2022.670 & 24.86932 & 2071.880 \\
\hline Hausman Test & Chi-Sq. Statistic & Chi-Sq. d.f. & Prob. \\
\hline Cross-section random & 18.282641 & 3 & 0.0004 \\
\hline
\end{tabular}

Fonte: elaboração dos autores, a partir da FINBRA/STN, 2012.

*Os erros-padrão das variáveis, expressos entre parênteses, foram estatisticamente significantes ao nível de $1 \%$.

Tabela 2 - Resultados estimados das despesas totais per capita, municipais do Rio Grande do Sul (2007-2010)

\begin{tabular}{|c|c|c|c|}
\hline \multirow{2}{*}{ Variável* } & \multicolumn{3}{|c|}{ Técnica de estimação com dados em } \\
\hline & $\begin{array}{l}\text { Estimador } \\
\text { agregado }\end{array}$ & Efeito fixo & $\begin{array}{l}\text { Efeito } \\
\text { aleatorio }\end{array}$ \\
\hline Intercepto & $\begin{array}{r}1.234664 \\
(0.041397)\end{array}$ & $\begin{array}{r}1.539486 \\
(0.042314)\end{array}$ & $\begin{array}{r}1.405810 \\
(0.037608)\end{array}$ \\
\hline Despesa com pessoal per capita & $\begin{array}{r}0.722541 \\
(0.009308)\end{array}$ & $\begin{array}{r}0.714007 \\
(0.010369)\end{array}$ & $\begin{array}{r}0.722131 \\
(0.008871)\end{array}$ \\
\hline $\begin{array}{l}\text { Despesa com investimento per } \\
\text { capita }\end{array}$ & $\begin{array}{r}0.185781 \\
(0.004177)\end{array}$ & $\begin{array}{r}0.130936 \\
(0.004052)\end{array}$ & $\begin{array}{r}0.150828 \\
(0.003663)\end{array}$ \\
\hline Despesa social per capita & $\begin{array}{r}0.044410 \\
(0.005578)\end{array}$ & $\begin{array}{r}0.057836 \\
(0.006444)\end{array}$ & $\begin{array}{r}0.051454 \\
(0.005454)\end{array}$ \\
\hline $\mathrm{R}^{2}$ & 0.934305 & 0.977821 & 0.935175 \\
\hline Estatística F & 9101.928 & 131.4415 & 9232.689 \\
\hline Hausman Test & Chi-Sq. Statistic & Chi-Sq. d.f. & Prob. \\
\hline Cross-section random & 141.873889 & 3 & 0.0000 \\
\hline
\end{tabular}

Fonte: elaboração dos autores, a partir da FINBRA/STN, 2012.

*Os erros-padrão das variáveis, expressos entre parênteses, foram estatisticamente significantes ao nível de $1 \%$. 
Tabela 3: Resultados estimados das despesas totais per capita, municipais de Santa Catarina (2007-2010)

\begin{tabular}{l|rrr}
\hline \multirow{2}{*}{ Variável* } & \multicolumn{3}{|c}{ Técnica de estimação com dados em } \\
\cline { 2 - 5 } & $\begin{array}{c}\text { Eannel } \\
\text { Estimador }\end{array}$ & Efeito fixo & $\begin{array}{c}\text { Efeito } \\
\text { aleatorio }\end{array}$ \\
\hline Intercepto & 0.956759 & 1.254800 & 1.169351 \\
& $(0.051226)$ & $(0.047495)$ & $(0.043726)$ \\
Despesa com pessoal per capita & 0.796255 & 0.792056 & 0.793968 \\
& $(0.010012)$ & $(0.009159)$ & $(0.008356)$ \\
Despesa com investimento per & 0.173700 & 0.141403 & 0.149269 \\
capita & $(0.004771)$ & $(0.003940)$ & $(0.003713)$ \\
Despesa social per capita & 0.019397 & 0.009366 & 0.012846 \\
& $(0.003131)$ & $(0.003600)$ & $(0.003087)$ \\
$\mathrm{R}^{2}$ & 0.945568 & 0.985619 & 0.953180 \\
Estatística F & 6253.743 & 203.3442 & 7328.999 \\
Hausman Test & Chi-Sq. Statistic & Chi-Sq. d.f. & Prob. \\
Cross-section random & 56.356915 & 3 & 0.0000 \\
\hline
\end{tabular}

FONTE: elaboração dos autores, a partir da FINBRA/STN, 2012.

*Os erros-padrão das variáveis, expressos entre parênteses, foram estatisticamente significantes ao nível de $1 \%$.

Em resumo, os resultados alcançados pelo modelo de dados em painel revelaram uma condição mais favorável para a gestão pública municipal paranaense, visto que mesmo tendo um panorama não muito diferente dos entes gaúchos e catarinenses, os municípios do PR apresentaram menores níveis de custeio da máquina e maiores patamares de dispêndios dedicados as áreas sociais, necessitando, no entanto, de elevar a taxa de investimentos públicos, conforme sugere Araújo (2006), quando ressalta a importância dos gastos governamentais para a atividade econômica.

As entidades municipais do RS e SC, ainda que tenham apresentado resultados relevantes quanto aos dispêndios com investimento por habitante, os níveis de gastos com pessoal torna o conjunto das despesas bastante rígido, dificultando sobremaneira a ação dos governos locais na provisão de bens públicos para os munícipes, necessitando, porém que os gestores dessas unidades federativas venham a reduzir seus dispêndios no custeio da máquina e alocar, principalmente, ao contexto social, podendo melhorar assim os níveis de desenvolvimento sócio econômico da região.

Após essas análises, alguns argumentos fazem-se necessários, a saber: de fato, o estado paranaense alcançou o melhor desempenho diante de SC e $\mathrm{RS}$ no tocante ao perfil dos gastos totais municipais por habitante. Assim, os gestores dos municípios do $\mathrm{PR}$ apresentaram durante o período examinado uma mais adequada convergência das despesas em relação ao disposto na LRF, possibilitando concluir que a força institucional reguladora do contexto fiscal exibiu certa efetivação.

Outro aspecto relevante diz respeito ao ambiente fiscal municipal, pois esse é caracterizado por uma propensão dos entes em gastar mais com folha de pagamento que nas demais áreas, gerando o que denomina Silva (2009) de produto marginal decrescente do funcionalismo público, ou como ressaltam Maia 
Gomes e Mac Dowell (1995), que afirmam ser improdutivo o trabalho junto ao serviço público municipal.

Daí a compreensão de que as instituições contribuíram para a realidade fiscal dos entes municipais, já que, a CF de 1988 gerou uma tendência de expansão dos gastos públicos de maneira desordenada em virtude do descentralismo, restando a LRF corrigir tal desordem via aspectos punitivos, conforme constata Silva (2009). Porém, ainda se reserva uma significativa possibilidade de melhorias no comportamento dos dispêndios municipais, de acordo com o alcançado nos resultados deste estudo.

Portanto, verificou-se que a magnitude das despesas municipais dos estados da região Sul mostrou uma propensão visivelmente mais significativa nos dispêndios com pessoal, em detrimento as demais rubricas, permitindo concluir que o alcançado nesta pesquisa se aproxima em muito da realidade administrativa pública presente nessas unidades federativas, pois foi possível constatar tal comportamento em termos per capita, permitindo compreender o perfil das finanças públicas municipais em regiões tidas como mais desenvolvidas.

\section{Considerações finais}

Tendo sistematizado esta pesquisa, a qual teve por objetivo examinar o poder regulatório presente na CF de 1988 e LRF sobre as despesas municipais dos estados do Sul brasileiro verificaram-se a presença institucional não desprezível advinda das regulações antes enfatizadas, de modo que os gastos realizados seguiram uma trajetória em parte convergentes com essas instituições.

Assim, um primeiro aspecto partiu da notável pouca inflexibilidade dos dispêndios voltados ao custeio da máquina municipal, dando mostras de que as administrações públicas desses entes reservam a maior parcela de seus recursos para manter o funcionamento da gestão governamental, ainda que absorvendo funcionários com reduzida produtividade. Isso se deve ao fato de que o descentralismo fiscal criou uma cultura administrativa fortemente voltada ao inchaço da máquina pública municipal com pessoal, cuja CF de 1988 institucionalizou esse comportamento dos gestores.

Claramente, o advento da LRF, na condição de uma instituição capaz de diminuir a proporção das despesas com folha de funcionários, disciplinando esse expediente administrativo municipal, alcançou, conforme a literatura aponta resultados relevantes, mas que ainda resta muito por fazer, notadamente, no que se refere à conquista de uma redução dos gastos nessa área ligada ao custeio e a consequente elevação das despesas com investimento e as rubricas relativas ao conjunto social. 
A conservação desse comportamento fiscal dos municípios analisados gera inconsistências econômicas, visto que, gastos fora do escopo dos investimentos não produzem crescimento e, portanto, o surgimento de novas oportunidades de emprego, além de que uma ausência de dedicação de maiores gastos na variável social (construída neste estudo) impossibilita uma mais adequada preocupação dos governos na provisão de políticas de cunho desenvolvimentistas, fundamentais de serem formuladas pelos municípios, em que os considerados no artigo não são diferentes desse aspecto.

Afinal, a hipótese do artigo é aceita, visto que, os gastos por habitante seguiram o esperado na pesquisa, de modo que a LRF, neste aspecto não foi tão efetiva, mas essa regulamentação produziu pelo menos uma tendência a uma maior austeridade, cujo reflexo disso decorreu dos reduzidos níveis dos dispêndios vinculados aos investimentos e as áreas sociais, comparativamente às despesas com pessoal, garantindo dessa forma a não rejeição da hipótese desta investigação.

Em síntese, o alcançado nesta pesquisa aponta para uma continuidade de uma incoerência administrativa dos governos municipais dos estados do Sul brasileiro, mesmo em um ambiente institucional conforme é desenhado pela CF de 1988 e retificado no contexto fiscal pela LRF. Assim, nota-se que a normatização de natureza fiscal tem alcance bastante limitado no controle e ordenação das finanças públicas dos municípios considerados no estudo, necessitando, realmente, restringir maiores gastos de custeio e de forma equivalente, aumentar as despesas com investimento e aquelas direcionadas ao contexto social, deflagrando uma nova modalidade de gestão de municípios.

Finalmente, sugere-se para futuras pesquisas a adoção de outros modelos econométricos, que venham a fornecer eventuais resultados mais robustos do que os constantes neste artigo; além disso, sugestiona-se que se considere uma relação, entre as variáveis de natureza fiscal, de modo que, as receitas orçamentárias sejam explicadas pelas rubricas de despesas propostas no trabalho; afinal, semelhantemente as demais investigações, essa igualmente limitada, permitiram compreender o panorama dos gastos municipais do Sul do país, destacando esta importante temática advinda das finanças públicas.

\section{Referências}

Affonso, R. de B. A. (2003). O Federalismo e as Teorias Hegemônicas da Economia do Setor Público na Segunda Metade do Século XX: Um Balanço Crítico. Campinas. Tese de Doutorado. Instituto de Economia. Unicamp.

Afonso, J. R; Serra, J. (1999). "Federalismo Fiscal à Brasileira: Algumas Reflexões. Revista do BNDES. Rio de Janeiro: BNDES, n. 12, dez./1999.

Araújo, H. V. de. (2006). Análise Comparativa do Gasto Social Brasileiro por Índices de Retornos Tributários. IX Prêmio do Tesouro Nacional Blanchard, O. (2004). Macroeconomia. 3 ed. São Paulo: Prentice Hall. 
Cintra, M. A. M. (2005) Suave Fracasso: A Política Macroeconômica Brasileira entre 1999 e 2005. Revista Novos Estudos - CEBRAP, vol. 73. Novembro/2005.

Friedman, M. (1985). Capitalismo e Liberdade. 2 ed. São Paulo: Nova Cultura.

Fioravante, D. G.; Pinheiro, M. M. S.; Vieira, R. S. (2006). "Lei de Responsabilidade Fiscal e finanças públicas municipais: impactos sobre despesas com pessoal e endividamento". Texto para Discussão: IPEA, n. 1.223. Brasília.

Gerigk, W. (2008). O impacto da lei de responsabilidade fiscal sobre a gestão financeira dos pequenos municípios do Pará. (Dissertação de Mestrado) Programa de Mestrado em Contabilidade do Setor de Ciências Sociais Aplicadas da Universidade Federal do Paraná. Curitiba.

Greene, W. H. (2003). Econometrics analyis, $5^{\mathrm{a}} \mathrm{ed}$, MIT Press. Cambridge, Massachusetts.

Gujarati, D. N; Porter, D. C. (2011). Econometria Básica. Tradução da $5^{\mathrm{a}}$ edição. Porto Alegre: AMGH.

Hermann, J. (2006). “Ascensão e Queda da Política Fiscal: De Keynes no "Autismo Fiscal” dos Anos 1990-2000". Rio de Janeiro: Instituto de Economia/UFRJ.

Johnston, J.; Dinardo, J. (2001). Métodos Econométricos. Lisboa: McGraw Hill.

Kennedy, P. (2009). Manual de Econometria. Tradução da $6^{\text {a }}$ edição americana. Rio de Janeiro: Elsevier.

Lopreato, F. L. C. (2002). O colapso das finanças estaduais e a crise da federação. São Paulo: Editora UNESP, IE, Unicamp

Lopreato, F. L. C. (2007). A Política Fiscal Brasileira: Limites e Entraves ao Crescimento. Instituto de Economia/UNICAMP. n 131, agosto.

Maia Gomes, G; Mac Dowell, M. A. (1995). Os Elos Frágeis da Descentralização: Observações Sobre as Finanças dos Municípios Brasileiros.

Matos Filho, J.; Silva, W. G.; Viana, F. C. (2008). "Caráter Institucional da LRF Para os Municípios do RN, BA, PI: Um Estudo Comparativo do Desempenho das Finanças Públicas Desses Entes Federativos, no Período 2000/2005”. IV Seminário Internacional sobre Desenvolvimento Regional. Anais... Santa Cruz do Sul: $22-24$ out.

Rangel, M. de A. (2003). Resgates financeiros, restrição orçamentária fraca e postura fiscal dos estados brasileiros. Rio de Janeiro: BNDES.

Rezende, F. (2001). Finanças Públicas. 2.ed. São Paulo: ATLAS.

Riane, F. (2002). Economia do Setor Público: Uma Abordagem Introdutória. 4. ed. São Paulo: Atlas.

Santolin, R.; Jaime JR, F. G.; Reis, J. C. dos. (2009). "Lei de Responsabilidade Fiscal e Implicações na Despesa de Pessoal e de Investimento nos Municípios Mineiros: Um Estudo com Dados em Painel Dinâmico". Estudos Econômicos, São Paulo, v, 39, $\mathrm{N}^{\mathrm{o}} 4$, p. 895-923, out/dez, 2009. 
Sena, L. B.; Rogers, P. (2007). "Análise agregada dos municípios mineiros de grande porte quanto à adequação à lei de responsabilidade fiscal (LRF)”. XIV Congresso Brasileiro de Custos - João Pessoa - PB, Brasil, Anais... 05 de dezembro a 07 de dezembro de 2007. CD-ROM.

Silva, W. G. (2009). Finanças públicas na nova ordem constitucional brasileira: uma análise comportamental dos municípios potiguares nos anos antecedentes e posteriores a Lei de Responsabilidade Fiscal (LRF). Dissertação de Mestrado em Economia. Universidade Federal do Rio Grande do Norte.

Silva, W. G.; Silva, S. C.; da.; Figueiredo, J. de S. (2011). "Comportamento dos municípios distribuídos por mesorregiões potiguares: uma relação entre a diferenciação regional e a capacidade alocativa no ano de 2008”. Encontro em Economia e Desenvolvimento do Agreste de Pernambuco - ENEDAP. Anais... Caruaru.

Silva Filho, L. A; Queiroz, S. N; Silva, W. G. Silva, A. O. F. (2010) "Receitas Correntes em Municípios Cearenses: Autonomia ou Dependência?" Revista Controle, $\mathrm{N}^{\circ} 1$, vol. VIII setembro de 2010.

Silva Filho L. A., Silva, W. G., Silva, A. O. F. E., Silva Y. C. L. (2011). “Considerações sobre receitas municipais em estados do Nordeste: comparação entre Bahia, Ceará e Piauí - 2007”. Revista Econômica do Nordeste. v.42, p.409 - 424. 
